\title{
Article \\ Dental Anxiety and Stress in Patients during Different Types of Oral Surgery
}

\author{
Patricia Richter ${ }^{1}$, Christin Bohl $^{2}\left(\mathbb{D}\right.$ and Hendrik Berth ${ }^{2, *}$ \\ 1 Praxis für Oralchirurgie Ates, Gotenring 1, D-50679 Cologne, Germany; patricia-wieschollek@web.de \\ 2 Research Group Applied Medical Psychology and Medical Sociology, Division of Psychological and Social \\ Medicine and Developmental Neurosciences, Carl Gustav Carus Faculty of Medicine, Technische Universität \\ Dresden, Fetscherstr. 74, D-01307 Dresden, Germany; christin.bohl@uniklinikum-dresden.de \\ * Correspondence: h.berth@ukdd.de
}

check for

updates

Citation: Richter, P.; Bohl, C.; Berth,

H. Dental Anxiety and Stress in

Patients during Different Types of

Oral Surgery. Oral 2022, 2, 88-94.

https://doi.org/10.3390/oral2010010

Academic Editor: Hessam Nowzari

Received: 29 December 2021

Accepted: 16 February 2022

Published: 21 February 2022

Publisher's Note: MDPI stays neutral with regard to jurisdictional claims in published maps and institutional affiliations.

Copyright: (C) 2022 by the authors. Licensee MDPI, Basel, Switzerland. This article is an open access article distributed under the terms and conditions of the Creative Commons Attribution (CC BY) license (https:// creativecommons.org/licenses/by/ $4.0 /)$.

\begin{abstract}
The aim of this study is to capture the dental anxiety of patients in a dental clinic. A special focus was placed on the measurement of the course of possible anxiety occurring during a single dental visit with different surgical procedures. Therefore, 129 patients were interviewed in an oral surgical clinic. The course of possible anxiety was measured with a short questionnaire about the current stress ("Kurzfragebogen zur aktuellen Beanspruchung", KAB), which was completed by the patients at three different times in the waiting room, as well as before and after the treatment in the consulting room. In the waiting room, the patient answered a questionnaire, including the following instruments: questions about age and sex, KAB (stress), and the Dental Anxiety Scale (DAS, anxiety). According to the DAS, $64.1 \%$ belonged to the low-anxiety group, $29.7 \%$ belonged to the medium-anxiety group and $6.2 \%$ belonged to the high-anxiety group. For all groups, the stress just before the treatment was the highest and it was the lowest after treatment. The KAB values of the female patients were significantly higher than those of the male patients. About one third of the patients suffered from dental anxiety.
\end{abstract}

Keywords: dental anxiety; dental stress; dental patients; oral surgery

\section{Introduction}

The basic feeling of anxiety is perceived differently and individually by every person. The different ways to deal with this anxiety are as vast and varied as the subsequent reactions. In response to anxiety-provoking objects or situations, there are controlled as well as uncontrolled actions or behaviors of patients. It should be emphasized that anxiety is normal, considering the perspective of evolution and is usually perceived as negative. However, developing a phobia out of an anxiety makes the patient often respond with an avoiding strategy, e.g., avoiding the dentist. The transition to this pathological condition is fluent [1].

Anxieties and their disorders are one of the most frequent psychological illnesses. Dental anxiety for patients who are suffering from an anxiety disorder is ranked in second place, with $21 \%$, behind the fear of public speaking, with $27 \%$ [2,3]. The distribution of dental anxiety among the German population can be estimated as follows: Approximately $60-80 \%$ have a sense of fear of visiting the dentist [4]. According to estimates, 5 to $10 \%$ of the population avoid dental treatment completely [1]. A study from 2019 aimed to show a relationship between dental anxiety and general psychological distress. It suggested that there is more psychological distress among patients below the age of 46 and women [5]. Additionally, patients with dental anxiety have more destroyed teeth and worse dental hygiene than other patients. It is, therefore, advised to figure out a suitable treatment of patients with dental anxiety to prevent bad oral health [6-8]. One can conclude that dentists need to be prepared for encounters with patients with dental anxiety and to act appropriately to reduce the anxiety [5]. 
The dental phobia is within the ICD-10 included in the specific phobias [9] and is based on a complex response pattern at multiple levels. "The specific phobia is a persistent, inappropriate and intense fear as well as the avoidance of specific objects or situations" [10] (p. 972). According to Öst, specific phobias arise in the first two decades of life. However, the average age of the beginning of a dental anxiety is at the age of twelve [11].

Dental anxiety describes the fear of the situation itself, in the sense of defeat, and the associated loss of control. This dental anxiety is often mistakenly referred to as dental fear, although there is no direct fear of the dentist as a person [1]. For patients with a dental phobia, the anxiety of the dental treatment and the main focus are the associated consequences.

The aim of this work is to capture the dental anxiety of patients in a dental clinic that specializes in oral surgery in a rural area. Furthermore, a special focus was placed on the measurement of possible anxiety occurring during a dental visit. The novelty value of the study consists of measuring the subjective anxiety of the patients three times over the course of the usual oral surgical treatment. Therefore, by means of standardized questionnaires, $\mathrm{N}=129$ patients were interviewed within 5 weeks in an oral surgical clinic in Wissen (Rhineland-Palatinate, Germany).

\section{Materials and Method}

\subsection{Study Design and Recruitment of Participants}

Within five weeks, during the period from July 2013 to August 2013, all patients of one private oral surgery clinic were asked to participate in the survey. The survey began in the waiting room where they filled out a comprehensive questionnaire. The questionnaire included, inter alia, the following instruments: Questions about age and sex, the short questionnaire to the current stress (KAB, "Kurzfragebogen zur aktuellen Beanspruchung", [12]), the Dental Anxiety Scale (DAS) [13], as well as a master data sheet with the socio-demographic data of the specific patient. After that, they took a seat on the dental chair. Before the dentist came and started the treatment, they filled in the KAB a second time. After the individual treatment, the patient had to fill in the short questionnaire to the current stress $\mathrm{KAB}$ a third and last time and could leave the dental clinic. The general conditions to take part in the survey were an age of 18 years or older, an adequate comprehension of spoken and written German and psychological inconspicuousness. A special screening for psychological problems was not part of this study. Dental phobia or a high level of dental anxiety were not exclusion criteria. All the study participants provided written informed consent.

\subsection{Questionnaires}

The focus of this study is the stress patients go through during a dental visit. Therefore, the well established questionnaire "Kurzfragebogen zur aktuellen Beanspruchung" KAB was used [12]. The patients had to fill in this short six-item questionnaire at three different times in two different places: In the waiting-room and in the consulting room before and directly after the treatment. The time span between the three measurement points ranged between 5 and $90 \mathrm{~min}$ for the individual patients, depending on the surgical treatment. The exact time period was not accurately measured and recorded. The instruction read "Please indicate how do you feel in this moment". The items read: (1) "strained" ... "calm", (2) "relaxed" .. "anxious", (3) "worried" .. "unconcerned", (4) "tense" .. "restless", (5) "skeptical" ... "trusting" and (6) "comfortable" ... "uncomfortable". Patients had to rate their feelings on a six-point Likert scale (range 1 to 6 ). The values of the 6 items were added up and divided by 6 . The value range for the KAB total score is 1 to 6 , whereby higher values indicate higher tension. The internal consistency of the KAB is Cronbach's alpha $=0.80$ [14].

We collected data on the intensity of participants' fear of dental treatment by using the international widespread Dental Anxiety Scale (DAS) [13,15]. The DAS consists of four questions (e.g., "Imagine you are sitting in the waiting room of the dentist: How do you 
feel?"). Patients rate their anxiety level in the different situations on a five-point Likert scale from "relaxed" to "anxious". The reliability of the DAS is $r=0.94$ [15]. The range of the scale is 4 to 20 . Using the DAS value, patients can be divided into three groups: no/low (4-10 points), moderate (11-15 points) or high dental anxiety (16 or more points) [15]. Scores higher than 10 points might be an indicator for dental phobia [15].

\subsection{Statistical Analysis}

The data were evaluated statistically using SPSS 21. The mean differences were calculated by the analysis of variance (ANOVA) and $t$-test. The relationships between the different variables were calculated by correlation (Pearson). Statistical differences were considered significant with a $p$-value $<0.05$ unless otherwise stated. The $\mathrm{G}^{*}$ power program [16] was used to calculate an appropriate sample size for the desired statistical analyses. Based on an effect size of $d=0.60$, a significance level of $p=0.05$ and power of $0.95 \%(1-\beta=0.95)$, a minimum sample size of $N=64$ per group (total $N=128$ ) was required for Pearson's correlations (two independent Pearson's r values).

\section{Results}

\subsection{Demographic Characteristics}

The survey results are based on the data of $\mathrm{N}=129$ patients, including 62 males and 67 females. Thus, the percentage of female patients of $51.9 \%$ is slightly higher than the male patients' $(48.1 \%)$. The mean age was 41.8 years (standard deviation (SD) $= \pm 18.3$ ). The age of the men, at 42.9 years $(\mathrm{SD}= \pm 18.3)$, was slightly higher compared to the age of the woman, at 40.8 years $(\mathrm{SD}= \pm 18.45)$. The patients included in the study had different oral surgical treatments, including, among other things, fillings, removal of wisdom teeth, extraction of teeth or the treatment of inflammation. All patients were treated with local anesthesia or without any anesthesia. Patients who visited the clinic for the preparation of a surgical treatment or for a checkup after a surgical treatment were also included in the study.

\subsection{Changes in the Level of the Current Stress}

The values of the KAB total scores show moderate correlations with the values of the DAS (see Table 1).

Table 1. Correlations (Pearson) between dental anxiety (DAS) and the values of KAB total scores I, II and III (waiting room, dental chair before treatment and dental chair after treatment).

\begin{tabular}{cl}
\hline KAB I, II and III & DAS \\
\hline 1. (waiting room before treatment) & $\mathrm{r}=0.532, p=0.000$ \\
\hline 2. (dental chair before treatment) & $\mathrm{r}=0.474, p=0.000$ \\
\hline 3. (dental chair after treatment) & $\mathrm{r}=0.234, p=0.008$ \\
\hline
\end{tabular}

These correlations illustrate that the $\mathrm{KAB}$ is suitable to control the trend of the current stress respective of the level of anxiety. Figure 1 shows the values of the KAB of the DAS groups divided into low, moderate and high anxiety and the group in total. According to the DAS, $\mathrm{N}=83(64.1 \%)$ belonged to the low-anxiety group, $\mathrm{N}=38(29.7 \%)$ belonged to the medium-anxiety group and $\mathrm{N}=8(6.2 \%)$ belonged to the high-anxiety group. On average, the graph increases from KAB I (waiting room before treatment) to the KAB II (dental chair before treatment). After the treatment (KAB III, dental chair after treatment) the value falls again, significantly. Thus, it reaches its highest point at KAB II and its lowest point at KAB III. The DAS shows that highly anxious patients have a higher KAB value and a higher stress than the medium- or low-anxiety patients. The value of the total group lies between the values of low- and medium-anxiety patients. The KAB was filled in three different times. In all groups, Figure 1 shows a climax and turning point in the KAB II value. KAB III 
was lower than the KAB I value (ANOVA for the anxiety groups: $\mathrm{KAB}$ I: $\mathrm{F}(\mathrm{df}=2)=24,974$, $p=0.000$; KAB II: $\mathrm{F}(\mathrm{df}=2)=18,535, p=0.000$; KAB III: $\mathrm{F}(\mathrm{df}=2)=3958, p=0.022)$.

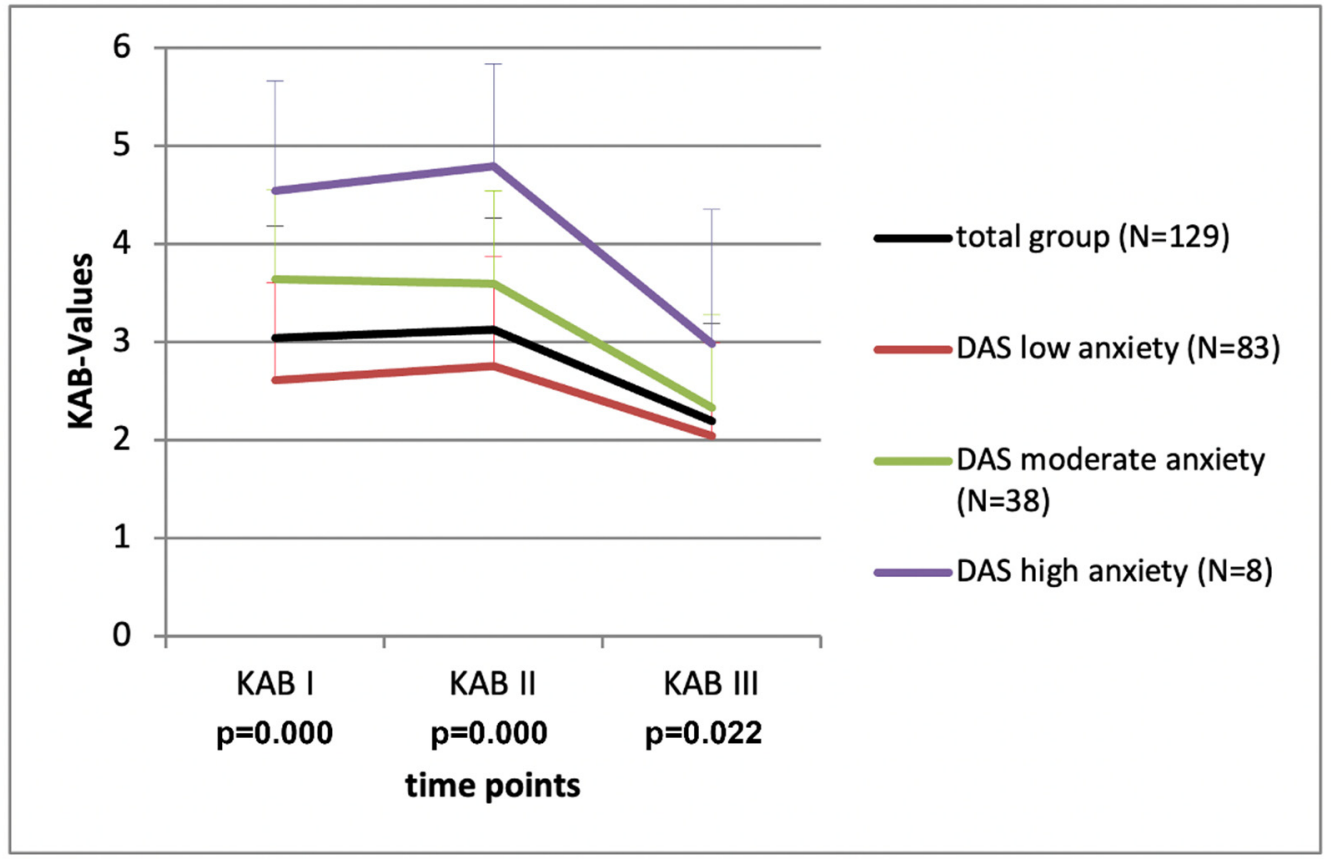

Figure 1. Stress of the patients (means \pm standard deviations, KAB) at three different times in dependent on the level of anxiety (DAS) of the patients.

Figure 2 illustrates the $\mathrm{KAB}$ values of the male and female participants at three different places and times. The significant result shows that, on average, women indicate higher stress levels than men $(\mathrm{KAB}$ I: $\mathrm{T}(\mathrm{df}=127)=-3779, p=0.000 ; \mathrm{KAB}$ II: $\mathrm{T}(\mathrm{df}=127)=-3294$, $p=0.001 ; \mathrm{KAB}$ III: $\mathrm{T}(\mathrm{df}=127)=-2226, p=0.028)$.

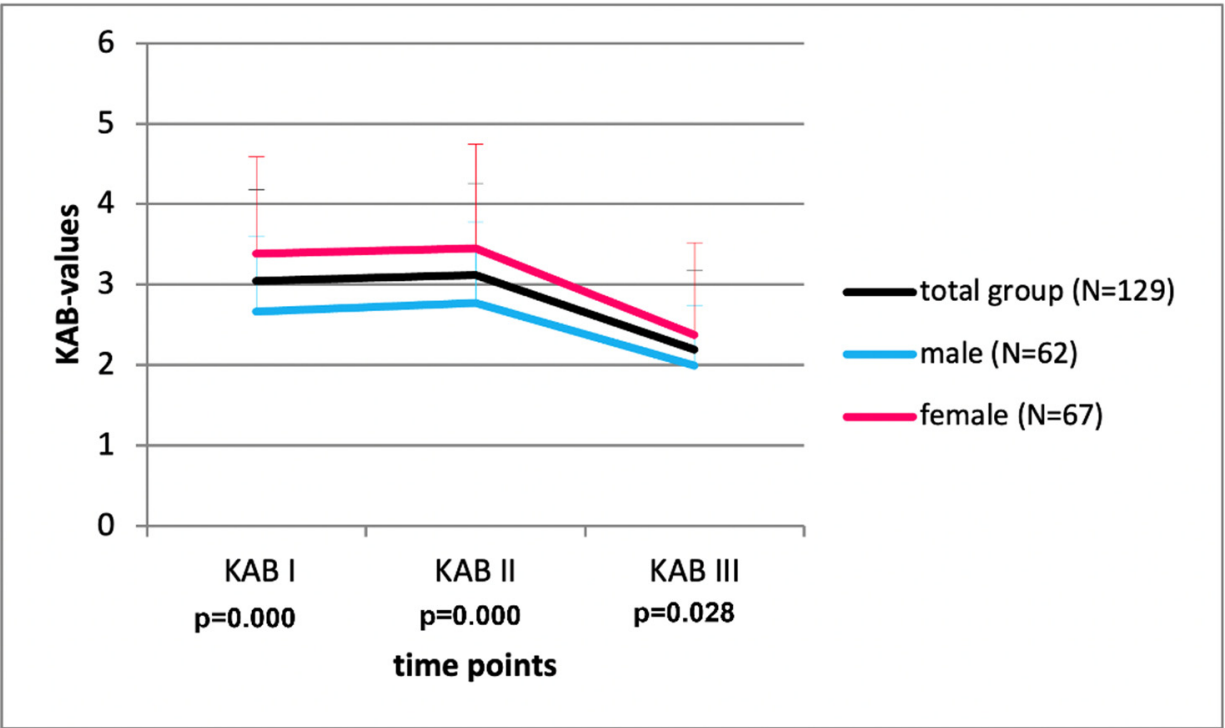

Figure 2. Stress of the patients (means \pm standard deviations) at three different times dependent on the gender of the patients.

\section{Discussion}

Jöhren and Margraf-Stiksrud [4] pointed out that up to $20 \%$ of the general population are considered to be highly anxious and 5\% avoid visiting the dentist completely. In this 
study on oral surgery patients who already entered the clinic and agreed to an oral surgery treatment, the group of highly anxious patients is unsurprisingly below $10 \%$. This deviation is due to the avoidance of visiting the dentist of anxious patients [1] and indicates that a valid result of the detection of anxious patients cannot be achieved without surveys outside the dental practice.

Particular attention was paid to the investigation of the stress profile of the patient. The instrument used for this purpose, the $\mathrm{KAB}$, is a proven method in extensive studies and is valid and reliable [14]. The survey of patients at three different points in time showed that the stress level in the waiting room was lower than just before treatment on the dentist's chair. After treatment, the KAB value was the lowest. Significant results have to be noted for dental anxiety and gender analysis. The curve is significantly higher comparing the more anxious to the non-anxious and female to the male patients.

In the present study, the gender differences can be seen clearly; women have higher dental anxiety data than men. Other studies show the higher dental anxiety of women as well [17-27].

The questionnaires used in this study are very short, with four (DAS) and six items $(\mathrm{KAB})$, and could, therefore, be used in dental practice. The wording is very easy for the patients to understand. Both instruments have been tested many times in studies with very good results [12-15]. Our study was the first study to use the "Kurzfragebogen zur aktuellen Beanspruchung" KAB in dentistry. Furthermore, it was, to our knowledge, the first investigation that used these two questionnaires in combination.

The results of the study confirmed the expectations. Patients perceive the situation in the dental surgery before the surgical intervention as unpleasant and threatening, so increasing signs of fear could be stated. Female test subjects were more likely to admit their stronger fear than the male ones. This corresponds to the social stereotypes about the gender role behavior, which is apparently still widespread [28]. Nevertheless, this result cannot be generalized because Rowe and Moore [29] show in their studies that men are more afraid of dental treatment than women.

\section{Limitations}

For legal reasons, only patients were interviewed who had reached the age of 18 . However, dental anxiety develops in previous years, usually at the age of twelve [11], which could not be considered in the study.

In this study, the patients' self-evaluations were worked out using standardized questionnaires. It should be mentioned that the result of such a study can be influenced by incorrect information given by the respondents. In 1989, Glanzmann described a distortion tendency of questionnaires, caused by the effect of the participants giving socially desirable answers [30]. Only short self-assessment instruments were used for the patients' survey, while objective measuring instruments could not be used due to the limited resources and limited time that were available for the study. For the division of the DAS values, we used the scores for three groups, as suggested by Tönnies et al. [15] for the German version of the scale. Other studies used an alternative division into four anxiety groups [13].

Generally, it should be noted that the presented investigation is only a small study that was conducted on only $\mathrm{N}=129$ patients in a single oral surgical practice in a rural area. Such a relatively small survey does not allow generalizations.

Dental anxiety is always "the result of specific experiences of people and their complex, constantly taking place processing, depending on the personal circumstances of the person concerned" [31] (p. 56). The dentist, therefore, should avoid conceiving the whole problem only schematically. A good relationship of trust, which is established by honesty, is a prerequisite of a functioning dentist-patient relationship. This is also important because a dental treatment takes place in the intimate area (body contact to $0.5 \mathrm{~m}$ ), and, thus, the personal space around the patient is injured [32].

An existing dental anxiety is best treatable by psychological means. However, e. g., is the irritation of an unanesthetized nerve extremely painful? "Every normally sensitive 
person wants to avoid this, if possible. As such, it is psychologically almost striking if someone expecting a larger dental work feels no fear!" [33] (p. 179).

Author Contributions: H.B. constructed the study design. P.R. realized the acquisition of the data. $\mathrm{CB}$ revised the data set. P.R. wrote the first draft of the manuscript. C.B. and H.B. contributed to the manuscript drafting. All authors have read and agreed to the published version of the manuscript.

Funding: The research was conducted without any third-party financial support.

Institutional Review Board Statement: The study was conducted in accordance with the Declaration of Helsinki, and approved by the Ethics Committee of the Technische Universität Dresden, Germany (protocol code EK211062013, date of approval 11 June 2013).

Informed Consent Statement: Informed consent was obtained from all subjects involved in the study.

Data Availability Statement: The data presented in this study are available on request from the corresponding author. The data will be soon openly available in the repository "OpARA—Open Access Repository and Archive Technische Universität Dresden, Technische Universität Bergakademie Freiberg", https:/ /opara.zih.tu-dresden.de/xmlui/.

Acknowledgments: The authors would like to thank all patients for their participation in the study.

Conflicts of Interest: The authors declare that the research was conducted in the absence of any commercial or financial relationships that could be construed as a potential conflict of interest.

\section{References}

1. Jöhren, P.; Sartory, G. Zahnbehandlungsangst und Zahnbehandlungsphobie: Ätiologie, Diagnose, Therapie; Schlütersche: Hannover, Germany, 2002; ISBN 978-3877066133.

2. Malamed, S.F. Pain and anxiety control in dentistry. J. Calif. Dent. Assoc. 1993, 21, 35-38, 40-41.

3. Valdes-Stauber, J.; Hummel, K. The relationship between dental anxiety and other kinds of anxiety: A naturalistic, cross-sectional and comparative study. BMC Psychol. 2021, 9, 184. [CrossRef]

4. Jöhren, P.; Margraf-Stiksrud, J. Zahnbehandlungsangst und Zahnbehandlungsphobie bei Erwachsenen. Dtsche Zahnarztl Z 2002, $57,1-5$.

5. Zinke, A.; Hannig, C.; Berth, H. Psychological distress and anxiety compared amongst dental patients-Results of a cross-sectional study in 1549 adults. BMC Oral Health 2019, 19, 27. [CrossRef]

6. Zinke, A.; Hannig, C.; Berth, H. Comparing oral health in patients with different levels of dental anxiety. Head Face Med. 2018, 14, 25. [CrossRef] [PubMed]

7. Kassem El Hajj, H.; Fares, Y.; Abou-Abbas, L. Assessment of dental anxiety and dental phobia among adults in Lebanon. BMC Oral Health 2021, 21, 48. [CrossRef]

8. Goh, V.; Hassan, F.W.; Baharin, B.; Rosli, T.I. Impact of psychological states on periodontitis severity and oral health-related quality of life. J. Oral Sci. 2022, 64, 1-5. [CrossRef] [PubMed]

9. World Health Organization. The ICD-10 Classification of Mental and Behavioural Disorders: Diagnostic Criteria for Research; World Health Organization: Geneva, Switzerland, 1993; ISBN 978-9241544221.

10. Wittchen, H.; Hoyer, J. Klinische Psychologie \& Psychotherapie, 2nd ed.; Springer: Berlin/Heidelberg, Germany, 2011; ISBN 978-3642130182.

11. Öst, L. Age of onset in different phobias. J. Abnorm. Psychol. 1987, 96, 223-229. [CrossRef]

12. Müller, B.; Basler, H. Kurzfragebogen zur Aktuellen BEANSPRUCHUNG; KAB: Beltz, Weinheim, 1993.

13. Corah, N.L. Development of a dental anxiety scale. J. Dent. Res. 1969, 48, 596. [CrossRef] [PubMed]

14. Berth, H. Kurzfragebogen zur aktuellen Beanspruchung (KAB). In Psychologische Tests Für Mediziner; Berth, H., Balck, F., Eds.; Springer: Berlin/Heidelberg, Germany, 2003; pp. 148-149. ISBN 978-3-540-43503-7.

15. Tönnies, S.; Mehrstedt, M.; Eisentraut, I. Die Dental Anxiety Scale (DAS) und das Dental Fear Survey (DFS)—Zwei Messinstrumente zur Erfassung von Zahnbehandlungsängsten. Z Med. Psychol. 2002, 11, 63-72.

16. Erdfelder, E.; Faul, F.; Buchner, A. GPOWER: A general power analysis program. Behav. Res. Methods Instrum. Comput. 1996, 28, 1-11. [CrossRef]

17. Nippert, R. Wer hat Angst vor der zahnärztlichen Behandlung? In Angst und Angstabbau in der Zahnmedizin; Sergl, H.G., Müller-Fahlbusch, H., Eds.; Quintessenz: Berlin, Germany, 1989; pp. 63-69. ISBN 978-3876522319.

18. Wöller, W.; Alberti, L.; Bachmann, M.; Birkhoff, M. Die Angst vor dem Zahnarzt-Eine Befragung von Patienten. In Angst und Angstabbau in der Zahnmedizin; Sergl, H.G., Müller-Fahlbusch, H., Eds.; Quintessenz: Berlin, Germany, 1989; pp. 57-62. ISBN 978-3876522319. 
19. Liddell, A.; Locker, D. Gender and age differences in attitudes to dental pain and dental control. Community Dent. Oral Epidemiol. 1997, 25, 314-318. [CrossRef] [PubMed]

20. Mehrstedt, M. Ohne Angst zum Zahnarzt; Asanger: Heidelberg, Germany, 2002; ISBN 3-89334-386-5.

21. Schuller, A.A.; Willumsen, T.; Holst, D. Are there differences in oral health and oral health behavior between individuals with high and low dental fear? Community Dent. Oral Epidemiol. 2003, 31, 116-121. [CrossRef] [PubMed]

22. Enkling, N.; Marwinski, G.; Jöhren, P. Dental anxiety in a representative sample of residents of a large German city. Clin. Oral Investig. 2006, 10, 84-91. [CrossRef] [PubMed]

23. Heft, M.W.; Meng, X.; Bradley, M.M.; Lang, P.J. Gender differences in reported dental fear and fear of dental pain. Community Dent. Oral Epidemiol. 2007, 35, 421-428. [CrossRef] [PubMed]

24. Hakeberg, M.; Cunha, L. Dental anxiety and pain related to dental hygienist treatment. Acta Odontol. Scand. 2008, 66, 374-379. [CrossRef] [PubMed]

25. Liau, F.L.; Kok, S.; Lee, J.; Kuo, R.; Hwang, C.; Yang, P.; Lin, C.; Kuo, Y.; Chang, H. Cardiovascular influence of dental anxiety during local anesthesia for tooth extraction. Oral Surg. Oral Med. Oral Pathol. Oral Radiol. Endod. 2008, 105, 16-26. [CrossRef]

26. Sirin, Y.; Humphris, G.; Sencan, S.; Firat, D. What is the most fearful intervention in ambulatory oral surgery? Analysis of an outpatient clinic. Int. J. Oral Maxillofac. Surg. 2012, 41, 1284-1290. [CrossRef] [PubMed]

27. Dadalti, M.T.; Cunha, A.J.; Souza, T.G.; Silva, B.A.; Luiz, R.R.; Risso, P.A. Anxiety about dental treatment—a gender issue. Acta Odontol. Latinoam. 2021, 34, 195-200. [CrossRef] [PubMed]

28. Dhom-Frerking, M.; Sergl, H.G. Untersuchungen über die Auswirkung von Angst auf Schriftgröße und Schriftbild. In Angst und Angstabbau in der Zahnmedizin; Sergl, H.G., Müller-Fahlbusch, H., Eds.; Quintessenz: Berlin, Germany, 1989; pp. 29-37. ISBN 978-3876522319.

29. Rowe, M.M.; Moore, T.A. Self-report measures of dental fear: Gender differences. Am. J. Health Behav. 1998, 22, $243-247$.

30. Glanzmann, P. Methoden zur Messung von Angst und Ängstlichkeit. In Angst und Angstabbau in der Zahnmedizin; Sergl, H.G., Müller-Fahlbusch, H., Eds.; Quintessenz: Berlin, Germany, 1989; pp. 17-28. ISBN 978-3876522319.

31. Jäger, K. Behandlungsangst Beim Zahnarzt_Erfolgreich Intervenieren Mit Entspannung und Ablenkung; VDM Verlag Dr. Müller: Saarbrücken, Germany, 2006; ISBN 978-3865503060.

32. Ingersoll, B.; Schneller, T. Psychologische Aspekte der Zahnheilkunde; Quintessenz: Berlin, Germany, 1987; ISBN 978-3876522029.

33. Birner, U. Psychologie in der Zahnmedizin: Über das Verhalten und Erleben von Menschen in der zahnärztlichen Praxis: Grundlagen, spezielle Problemfelder; Lösungswege Quintessenz: Berlin, Germany, 1993; ISBN 978-3876522524. 